\title{
SUCCESSFUL APPROACHES TO PLACING AND SUPPORTING APPRENTICES AND TRAINEES WITH DISABILITY IN AUSTRALIA
}

*Dr Greg Lewis, Executive Director, EDGE Employment Solutions, 38 Hood Street, Subiaco, Western Australia 6008, Australia. Phone: +61 89286 6600. Fax: +61 89288 6699. Email: Greg.Lewis@edge.org.au.

Dr Stian H Thoresen, Research Associate, Centre for Research into Disability and Society, Curtin Health Innovation Research Institute, Curtin University of Technology, GPO Box U1987 Perth, Western Australia 6845, Australia. Phone: +61 892663745. Fax: +61 89266 3636. Email: S.Thoresen@curtin.edu.au.

Prof Errol Cocks, Director, Centre for Research into Disability and Society, Curtin Health Innovation Research Institute, Curtin University of Technology, GPO Box U1987 Perth, Western Australia 6845, Australia. Phone: +61 89266 3621. Fax: +61 8 9266 3636. Email: E.Cocks@curtin.edu.au.

*Corresponding author 


\begin{abstract}
This paper presents an amalgamation of three sequential research projects conducted by EDGE Employment Solutions over the past decade. The first project, commenced in 1999, was a local initiative to increase the number of apprentices and trainees with disability being supported by EDGE. The completion rate for participants in this project was equivalent to that of people without disability undertaking apprenticeships and traineeships in Australia. However, it was found that Group Training Organisations, who hire apprentices and trainees to then place them with different employers, did not have the necessary skills or resources to place and support people with disability. To fill this gap, the second research project, undertaken in 2002, surveyed all 180 Group Training Organisations operating in Australia. This was followed by a site visit of six GTOs who were most successful in their disability efforts, to discern best practice in placing and supporting apprentices and trainees with disability. The third research project, which built on the findings of the previous two projects, was initiated in 2003 and enlisted 20 Group Training Organisations and 20 Disability Employment Services from around Australia to form partnerships to capitalise on their complementary expertise and resources. Apprenticeship and traineeship completion rates for participants in the third project surpassed those for people without disability in Australia. This paper presents and discusses the successful strategies researched and developed through these three projects.
\end{abstract}

Key words: apprenticeship; Australia; disability employment service; people with disability; traineeship; vocational education and training. 


\section{Introduction}

It has been thirty years since the first employment programs to assist people with significant developmental disabilities to find and retain mainstream employment began to take root in North America [8, 14, 29, 42], Great Britain [13] and Australia [19]. Much has been achieved over the ensuing decades and many hundreds of thousands of people with significant disability around the world have successfully entered the economic mainstream. However, the vast majority of those workers are employed in unskilled positions at or below the prevailing wage levels. There is a growing danger that these workers will be left behind in the new 'knowledge economies' that value and reward recognised skills and qualifications. The implications for workers who do not possess such skills and qualifications is that they will be progressively consigned to the most menial, most casualised, most poorly paid and most marginalised positions in the general workforce: in essence, sheltered workshops without walls.

EDGE Employment Solutions Inc. (EDGE) has more than 25 years of experience as a Disability Employment Service (DES), having placed and supported more than 2,000 job seekers with intellectual, sensory, physical, neurological and psychiatric disability into almost 5,000 award (prevailing) wage jobs in and around Perth, Western Australia. EDGE operates under what is traditionally known as the 'place-then-train' model. This involves careful job matching (finding jobs that are well matched to the job seeker's abilities and interests), individualised marketing (finding the right job with the right employer in the right location for that job seekers), intensive on-the-job support (implementing powerful training technologies and utilising natural supports inside and outside the workplace, and long term follow-up with the worker.

These same techniques have been applied to several hundred apprentices and trainees 
supported by EDGE over the ensuing ten years. When the first apprenticeship research project was initiated by EDGE in 1999, a trades skills shortage was looming within Australia's then buoyant economy [9, 39]. A decade later there is a similar concern with regards to growing skills shortages in Australia [12].

\section{Background}

\subsection{Disability and employment in Australia}

In 2003 500,000 Australians aged 15 to 64 were classified as having a significant disability. This was defined as sometimes or always needing help with at least one of the core activities of daily living: mobility, self-care and communication [2].

Only 53.2 percent of people with disability were in the workforce, compared to 80.6 percent of people without disabilities in 2003 [1]. The unemployment rate for people with disability is also much higher than for people without disability: at 8.6 percent and 5.0 percent respectively. However, only 15.2 percent of people with significant disability, as defined above, were participating in the workforce. People with disability are over-represented among the unemployed $[1,16,17,37]$ and poor post-school outcomes are frequently reported [30]. Some recent studies have suggested a decreasing wage gap between employed persons with and without disability [10, 35, 36]. This may reflect an increased equity in salary levels following the emergence and persistence of DES service providers supporting and advocating on behalf of people with disability. There are many well-documented obstacles people with disability face when seeking employment, including inaccurate perceptions of their work capacities, stereotypical attitudes, prejudice and discrimination [16, 26, 27]. Australian research indicates that even employers who are positive to hiring people with disability are uncertain of their 
own capacities and capabilities to support an employee with disability and unaware of supports may be available [41].

\subsection{Apprenticeships and traineeships in Australia}

Apprenticeships and traineeships are work-based education courses and a subset of the broader spectrum of post-school vocational education and training (VET). In Australia, apprenticeships and traineeships are collectively referred to as Australian Apprenticeships and incorporate traditional trades and as well as more recently developed courses in business, retail, hospitality, industry and many other sectors. Generally, Certificate levels I and II take one to two years to complete. Certificates III and IV require three to four years of training [5, 31]. Courses involving three or more years are typically referred to as apprenticeships, while shorter courses are usually called traineeships. Certificates are awarded based on 'nationally endorsed competency standards' and reflect 'workplace performance' specific to their course [5]. Collectively, Group Training Organisations (GTOs) are the largest employer of Australian Apprentices and currently employ and support about 42,000 apprentices and trainees [15]. GTOs indenture (employ) the apprentice or trainee for the duration of the course and place them with various host employers during the course of their training on a labour hire basis. GTOs offer a number of benefits: businesses do not have to undertake training administration and payroll duties when hiring Australian Apprentices, they do not have to employ them for the full duration of the education and training, they can ask the involved GTO to take them back at any time, and the apprentice or trainee receives a much more rounded training experience.

\subsection{People with disability in apprenticeships and traineeships}


VET is an effective approach to enhancing the employability of people with disability and has been linked to positive outcomes [17, 32, 39, 40]. People with disability are significantly under-represented in apprenticeships in the traditional trades. A national US survey during the 1980s estimated that less than two percent, probably less than one percent, of apprentices had a disability [32].

People with disability are significantly under-represented in the Australian VET system $[3,4,18,22]$. In fact, they are the least represented of all the equity groups (which include Aboriginal people, people from culturally and linguistically diverse backgrounds, refugees and people from low socio-economic backgrounds). As a proportion of Australian Apprenticeship commencements from 1998 to 2008, apprentices and trainees with disability only represented between 1.2 percent and 2.3 percent for any given year [34]. By way of caution, it should be noted that disability status in these figures relied on self-report. The reported number of apprenticeships and traineeships commencements in 1998 was 154,998. This had almost doubled by 2008, when 288,998 apprenticeships and traineeships were commenced. Among these; 3,602 persons indicated they had a disability in 1998, while 4,443 apprentices and trainees declared a disability in 2008 [34].

It has been calculated that supporting people with disability to undertake and complete VET courses can lead to annual savings of up to 18.8 billion Australian dollars [3], equivalent to US\$17 billion. People with disability undertaking VET are also more likely to be participating in lower level Certificate I and II courses, which tend to be enabling courses and have no direct pathway to industry [3, 6, 11, 22].

Overall completion rates for apprentices and trainees from the 2002 and 2003 were 48.4 percent and 48.5 percent respectively [33]. Completion rates among apprentices and 
trainees with and without disability were estimated to be 42.1 percent and 46.1 percent respectively for the 1998-1999 cohort [7]. Thus, apprentices and trainees with disability were nine percent less likely to complete their courses. Whilst the comparative performance is not wildly dissimilar, there is obvious room for improvement in completion rates for apprentices and trainees with disability.

\section{Three sequential research projects}

\subsection{Western Australian Apprenticeship Project}

Background: A two year pilot study was initiated in mid-1999 to improve apprenticeship placements among job seekers with disability supported by EDGE, with a target to place 25-30 apprentices with disability over two years [23].

Methodology: A project co-ordinator was appointed to recruit candidates with disability and secure suitable apprenticeship positions within industry. In addition, EDGE sought to develop alliances with local two GTOs, as it was recognised that EDGE did not have an requisite VET expertise nor ready access to a network of employers who regularly took on apprentices [23]. In their turn, the GTOs saw this as an opportunity to improve their recruitment of candidates with disability. As the GTOs did not have an expertise in recruiting, marketing or supporting apprentices and trainees with disability, the partnership with EDGE was seen to be mutually beneficial.

Multiple approaches were used to attract people with disability who would be interested in undertaking an apprenticeship. In addition to reviewing its then register of 150 job seekers for potential candidates, EDGE placed several newspaper advertisements seeking new candidates. The first advertisement received more than 100 responses, and subsequent advertisements were scaled back. No advertisements were placed during the second year of the project, as referrals were at this stage being made form various 
service providers, including VET teaching institutions and other DES service providers [23].

Strategies and outcomes: Seventy persons with disability registered with the pilot project. Among these registrants, 28 were placed in apprenticeships and five were placed in traineeships during the course of the two-year project [23]. The strategies to place the participants were similar to those utilised generically by EDGE to securing award-paying jobs in open employment for people with disability. Eleven placements were secured by responding to advertised vacancies for apprentices and trainees; six through employer canvassing (where employers are approached without a vacancy having been advertised); six through repeat business (businesses where employers were already employing people with disability through EDGE); five through the contacts of the GTO partners; three through VET education providers; and two through the informal networks of the registrants. A disappointing aspect of the project was that only one of the 33 participants placed through the project was indentured by a GTO, despite five placements being generated within their host employer networks. The other four participants were directly indentured by the host employer [22]. Thus, while the candidacy of people with disability as legitimate apprentices had been established through the project, there was still a need to convince GTOs.

Table 1 outlines the characteristics of the apprentices and trainees, their courses and completion rates. It illustrates that 11 of the 28 apprentices and all of the five trainees successfully obtained certificates, although one of the apprentices ended up completing a traineeship. Thus, the combined completion rate for the apprentices and trainees in the WA pilot project was 48.5 percent. This is 6.4 percentage points better than among apprentices and trainees with disability and 2.4 percentage points better than apprentices 
and trainees without disability from the 1998-1999 cohort [7] and identical to the completion rate of all apprentices and trainees who commenced the training in 2003 [33].

This outcome suggests that disability does not have to be a hindrance to complete apprenticeships or traineeships. It is argued, however, that a combination of good job match, accommodating workplace and intensive post-placement support are crucial contributors to the high proportion of completions. Post-placement support included preparing the supervisor and co-workers for the arrival of the new apprentice, dealing with any concerns, recruiting their support to provide the necessary instruction and guidance, becoming familiar with the tasks the apprentice was expected to perform, arranging any needed workplace modifications or equipment aids, and assisting with the apprentices’ skill acquisition and general performance as and when required. Off-thejob support was also crucial as crucial contributor and included: overcoming VET education providers' objections to teaching apprentices with disability in their classes and arranging for interpreters, note-takers, tutors, mentors and/or equipment modifications as and when required [23].

\subsection{National GTO Disability Best Practice Project}

Background: The WA Apprenticeship Project, although successful in placing and supporting apprentices and trainees with disability failed to fully engage the participating GTOs. Acknowledging these challenges, the second research project endeavoured to uncover best practices among GTOs Australia-wide in placing and supporting apprentices and trainees with disability.

Methodology: An initial survey of all 180 GTOs operating around Australia was initiated in 2002 to identify GTOs with the largest number of registrants with disability, 
positing that most involved would be likely to have the most developed practices [20]. Based on the survey responses, 23 GTOs were identified as being actively involved with apprentices or trainees with disability. All three 23 GTOs agreed to participate in a structured telephone interview conducted by the first author. The survey revealed that, even amongst the most disability-engaged GTOs, only 69 of a total of 4,293 apprentices and 145 of 4,350 trainees registered with these GTOs had a disability. This represented just 2.5 percent of all registrants.

The types of disability represented amongst the indentured apprentices and trainees covered the spectrum for intellectual and learning, through psychiatric, sensory, physical and neurological. There was not a major disability group that was not represented.

The structured interviews identified six GTOs from amongst the 23 that exhibited good practice in recruiting, placing and/or supporting apprentices and trainees with disability. Each of these six GTOs agreed to a two-day site visits by the first author or one of two other experienced disability employment managers from other parts of Australia [20]. Outcomes and Findings: Based on the structured interviews, which included specific enquiries about every identified apprentice or trainee with a disability indentured by the GTO, it was found that 65 percent of the apprentices were rated by their employer (the GTO) as making good to very good progress and 85 percent of the trainees were rated as doing good to very good progress [21]. It was also revealed that, among these 23 GTOs, 20 had various types of partnerships (ranging from loose to strong and informal to formal) with local DES and that two of these received dual funding to enable them to operate as both a GTO and a DES [20]. Although two GTOs indicated some dissatisfaction over their relationships with DES, the majority were satisfied or very 
satisfied. The main product of this research project was a Best Practice Guide [21] based on findings from the six case studies [20], each of which were profiled in the guide. It was found that formal relationships cemented through Memorandums of Understanding (MOUs) which clarified the roles of the GTO and DES nurtured trust and confidence. In addition, cross-organisational training and knowledge sharing; involving local schools, utilise existing partners and professional networks; creating and disseminating joint disability appropriate information for prospective apprentices and trainees with disability; creating and disseminating joint marketing information and strategies for prospective employers; and capitalising on the supplementary expertise were identified as key success factors [21].

\subsection{National GTO/DES Partnership Project}

Background: Building on the experiences and findings of the first two projects, the third research project sought to recruit, place and support apprentices and trainees with disability through formal partnerships between GTOs and DES providers.

Methodology: GTOs and DES service providers were invited submit a joint application to participate in the national partnership project, which included submitting a suitable MOU based on the sample MOU included in the tender documentation. When the project was first initiated by EDGE and Group Training Australia (the GTO national peak body) in 2003, there was sufficient funding to launch and support 10 GTO and DES partnerships throughout Australia. However, due to the exceptionally high interest (with 30 applications being received), a second round of 10 additional partnerships was funded and advertised the following year. EDGE, delivered an one day workshop to management and staff from all participating GTOs and DES providers at the commencement the project. A total of 282 GTO and DES staff participated in one of the 
16 one-day workshops [24]. Each partnership had a target to place eight apprentices and trainees with disability over the two-year recruitment and placement period. EDGE provided a telephone and e-mail help-desk service to all the 40 partnership members and distributed quarterly e-newsletters to all participants that reported on the progress of each partnership, profiled individual partnerships and apprentices, provided general advice on common hurdles, and summarised help-desk enquiries it had received along with the advise dispensed.

Outcomes and Findings: Only 16 GTOs were surveyed at the completion of the project as two partnerships did not succeed in placing any apprentices or trainees, one GTO discontinued operations and one GTO had a change in management and did not want to continue the GTO’s participation in the research project.

A total of 216 candidates with disability were registered by the 16 surveyed partnerships over their two-year recruitment and placement periods [24]. During the course of the two years, 122 apprentices and trainees with disability placed by the 20 partnerships, comprising 38 apprentices and 84 trainees (see Table 1).

All active partnerships were surveyed one year and again two years into their recruitment and placement periods. As most apprenticeships take three or four years to complete, and some participants were undertaking their traineeships on a part-time basis over two years, 17 apprentices and trainees were still in training when the second rounds of the annual surveys were completed. The second annual survey afforded the opportunity to ask respondent GTOs to rate their continuing 17 apprentices and trainees with disability against other apprentices and trainees without disability employed by the GTO in the same courses of training. The GTOs rated overall progress of 59 percent of the apprentices and trainees with disability as very good and a further 29 percent as 
good. Compared to their non-disabled peers, the GTOs rated 94 percent were rated as equivalent or superior than on work safety; 88 percent equivalent or superior on work attitudes; 88 percent equivalent or superior on work attendance; 71 percent equivalent or superior on work supervision and training needs; 64 percent equivalent or superior on work competency; and 59 percent equivalent or superior on work productivity [24]. Thus, apprentices and trainees with disabilities supported through GTO/Disability Employment Services partnerships out-performed their non-disables peers on every key dimension of work and training.

The 17 continuing apprentices and trainees were followed up in 2010. In support of the GTO ratings, all but 3 of the 17 continuers successfully completed their training. Completion rates for all the apprentices and trainees in the national partnership project appear in Table 1. A total of 16 (out 38) apprentices and 51 trainees (out of 84) completed their course. This translates to a combined completion rate of 56.8 percent: 44 percent for apprentices and 62 percent for trainees. The progress of two apprentices and two trainees are unknown as the result of the GTO that ceased operating. The completion rate of 56.8 percent is 14.7 percentage points higher than apprentices and trainees with disability and 10.7 percentage points higher than apprentices and trainees without disability from the 1998-1999 cohort [7]; and 8.3 percentage points higher than for all apprentices and trainees who commenced their courses in 2003 [33].

\section{Discussion}

The three sequential research projects have demonstrated that apprentices and trainees with disability can, with appropriate support, complete their courses at comparable or superior rates to their non-disabled peers. Caution should be exercised in generalising these findings as the sample size of approximately 150 across the first and third projects 
is still relatively small. However, they have involved placement and support over a 10year period, have involved 40 different service providers across every state of Australia and have included every major disability group, a wide range of ages and more than 50 different apprenticeships and traineeships.

It should be noted that the increase in the completion rate from the WA Apprenticeship Project to the National Disability Partnership Project suggests improvement and refinement in the recruitment, placement and support technologies that were applied. It also suggests the benefits that can accrue to apprentices and trainees with disabilities when the skill and resource capabilities of generic apprenticeship/traineeship providers and specialist disability employment services, who traditionally have little to do with each other, are brought together to support this group.

There are three discrete processes involved in placing and supporting apprentices and trainees with disability to complete their courses: recruiting candidates and matching them to suitable apprenticeships and traineeships; placing apprentices and trainees in the right apprenticeship or traineeship with the right employer and/or host employer; and supporting apprentices and trainees on-site and a off-site for the duration of their courses.

Organisations that specialise in apprenticeships and traineeships (such as GTOs in Australia), or employers who directly indenture apprentices and trainees, will not usually have the inclination or the disability contacts to locate or attract candidates with disability. The DES can fulfil this vital role and, in addition, can pre-screen (i.e. job match) candidates prior to their referral to the employer. This also affords important safeguards to the candidate with disability as the employer and the workplace can also 
be pre-screened to determine general safety, accessibility and suitability of the workplace.

The DES also has a unique contribution to make in promoting candidates with disability to prospective employers. Other intermediaries, such as GTOs or generic job placement agencies, will usually provide a prospective employer (or host employer where a GTO is involved) with a several candidates and leave the final decision to the employer. If one of the candidates has a disability, the chances are remote that they will be the one selected by the employer [25]. The DES will (or should) encourage a partner agency to go forward with just the candidate with disability and make the case to the employer. The DES will also be more mindful of the fit between the candidate and the prospective employer from the perspective of suitability of the work environment as well as proximity to home and transport between job sites or training venues (as most will not have driver's licenses).

Most GTOs have a worksite visiting cycle of 6-8 weeks during which the focus is on general apprentice/trainee performance, progress with work related studies and general paperwork. Most apprentices and trainees with disability will require significantly more on-the-job and off-the-job support than the GTO can provide. The DES will provide intensive on-the-job support to ensure that the apprentice or trainee is learning the required skills in a timely and competent manner. The DES will also liaise closely with the VET training provider to support the theoretical aspects of the training course and to transfer that knowledge to the worksite.

The approach that was developed, researched and refined during the course of these three projects was to build partnerships between organisations with complementary expertise and resources. While the classifications of organisations described in this 
article are specific to the Australian context, building partnerships between DESs, VET education providers, industry groups and certification organisations can be replicated elsewhere. Several elements are required to make these partnerships meaningful. There needs to be a clear and shared understanding of the expectations and responsibilities among partners. This can be achieved through a well-crafted MOU that describes mutual responsibilities of the signatories. It is also necessary that staff across the partner organisations have a shared commitment to the partnership and the candidates that is seeks to support, a clear understanding and appreciation of the expertise of their partners, a commitment to work collaboratively and a willingness to resolve issues that may arise.

The organisations that were surveyed in the third project suggested a number of strategies to strengthen partnerships and improve outcomes. Pre-eminent amongst these strategies are regular contact between involved staff in each partner organisation and timely dissemination of information so staff in the different partner organisations have a clear understanding of each other's role and contribution. Some partner organisations designated staff to these specific tasks, i.e. a disability officer within a GTO or a dedicated marketing or job support person from the DES.

The more successful partnerships in the national partnership project also developed joint information brochures, cross-linked their web-sites and held joint meetings with prospective employers describing the merits and suitability of their candidate and outlining the roles of each organisation in supporting the candidate and the employer. This cemented the partnership and left the employer with the impression that he or she was not only getting a carefully matched and motivated apprentice or trainee, but also the support and back-up of two closely allied and complementary services. 


\section{Conclusions and further research}

This paper has outlined a number of strategies that have proven successful in placing and supporting apprentices and trainees with disability. Undertaking and completing apprenticeships and traineeships improves the skills and the subsequent employability of people with disability, creating more sustainable employment and greater income security. Further research will be undertaken to explore the long-term outcomes and subjective perceptions of several hundred EDGE's registrants who have commenced and completed apprenticeships and traineeships. EDGE currently auspices a project to place and support students with disability to undertake work experience placements that lead onto school-based apprenticeships and traineeships. A review of success factors of this project may also be of interest.

\section{Acknowledgements}

The authors would like to acknowledge the funding bodies of these three research projects: The Western Australian Department of Training for the WA Apprenticeship Project; the Australian National Training Authority for the National GTO Disability Best Practice Project ; and the Australian Government Department of Education Science and Training for the National GTO/DES Partnership Project. The authors would also like to acknowledge the significant contribution of Peter Goff to the WA Apprenticeship Project and Jeff Priday to the two national projects. 
Table 1: Number of apprentices and trainees with disability placed and completed

\begin{tabular}{|c|c|c|c|c|}
\hline & \multicolumn{2}{|c|}{$\begin{array}{c}\text { WA Apprenticeship } \\
\text { Project }\end{array}$} & \multicolumn{2}{|c|}{$\begin{array}{l}\text { National GTO/DES } \\
\text { Partnership Project }\end{array}$} \\
\hline & Commenced & Completed $^{1}$ & Commenced & Completed $^{2}$ \\
\hline \multicolumn{5}{|l|}{ Gender } \\
\hline Male & 29 & $15(52 \%)$ & 92 & $51(57 \%)^{3}$ \\
\hline Female & 4 & $1(25 \%)$ & 30 & $16(55 \%)^{4}$ \\
\hline \multicolumn{5}{|l|}{ Age } \\
\hline $15-19$ & 20 & $10(50 \%)$ & 74 & $42(57 \%)$ \\
\hline $20-25$ & 9 & $4(44 \%)$ & 30 & $16(53 \%)$ \\
\hline $26+$ & 4 & $2(50 \%)$ & 17 & $9(53 \%)$ \\
\hline Missing & - & - & 1 & Unknown \\
\hline Mean & 19.7 & 19.6 & 20.9 & 20.5 \\
\hline Median & 19 & 19 & 19 & 18 \\
\hline \multicolumn{5}{|l|}{ (Primary) Disability } \\
\hline Acquired Brain Injury & 1 & 0 & 3 & $1(33 \%)$ \\
\hline Attention Deficit / Hyperactive Disorder & 17 & $8(47 \%)$ & 4 & $2(50 \%)$ \\
\hline Autism & 1 & $1(100 \%)$ & 6 & $3(50 \%)$ \\
\hline Hearing Impairment & 2 & $1(50 \%)$ & 14 & $9(64 \%)$ \\
\hline Intellectual/Learning & 6 & $4(67 \%)$ & 65 & $38(59 \%)^{5}$ \\
\hline Neurological Disability & - & - & 4 & $2(50 \%)$ \\
\hline Physical Disability & 5 & $2(40 \%)$ & 7 & $5(71 \%)$ \\
\hline Psychiatric Disability & 1 & 0 & 13 & $4(40 \%)^{6}$ \\
\hline Vision Impairment & - & - & 4 & $1(25 \%)$ \\
\hline Unknown & - & - & 2 & $2(100 \%)$ \\
\hline Apprentices & 28 & $10(36 \%)^{1}$ & 38 & $16(44 \%)^{7}$ \\
\hline Agriculture & - & - & 1 & $1(100 \%)$ \\
\hline Automotive (All Forms) & 10 & $5(50 \%)$ & 2 & $1(50 \%)$ \\
\hline Baking (All Forms) & 4 & $1(25 \%)$ & 3 & $1(33 \%)$ \\
\hline Chef & 2 & $1(50 \%)$ & - & - \\
\hline Electrical (All Forms) & 1 & $1(100 \%)$ & 1 & $1(100 \%)$ \\
\hline General Construction (All Forms) & 2 & 0 & 9 & $4(44 \%)$ \\
\hline Hairdressing & 3 & 0 & 5 & $3(60 \%)$ \\
\hline Horticulture (All Forms) & 1 & 0 & 6 & $3(50 \%)$ \\
\hline Manufacturing / Engineering (All Forms) & 4 & $1(25 \%)^{1}$ & 8 & $2(33 \%)^{8}$ \\
\hline Meat Processing & - & - & 2 & 0 \\
\hline Plumber & 1 & $1(100 \%)$ & - & - \\
\hline Warehousing & - & - & 1 & 0 \\
\hline Trainees & 5 & $6(120 \%)^{1}$ & 84 & $51(62 \%)^{9}$ \\
\hline Aged Care & - & - & 1 & $1(100 \%)$ \\
\hline Agriculture (All Forms) & - & - & 8 & $7(88 \%)$ \\
\hline Asset Maintenance (All Forms) & - & - & 3 & $3(100 \%)$ \\
\hline Automotive (All Forms) & - & - & 6 & $3(50 \%)$ \\
\hline Business Administration & 5 & $6(120 \%)^{1}$ & 20 & $12(67 \%)^{10}$ \\
\hline Community Services (All Forms) & - & - & 2 & $1(50 \%)$ \\
\hline Food Processing (All Forms) & - & - & 3 & $1(33 \%)$ \\
\hline Furnishing (All Forms) & - & - & 5 & $2(40 \%)$ \\
\hline Horticulture (All Forms) & - & - & 13 & $8(62 \%)$ \\
\hline Hospitality (All Forms) & - & - & 6 & $2(33 \%)$ \\
\hline Library Services & - & - & 1 & $1(100 \%)$ \\
\hline Local Government & - & - & 1 & 0 \\
\hline Manufacturing / Engineering (All Forms) & - & - & 3 & $2(67 \%)$ \\
\hline Printing and Graphic Arts & - & - & 3 & $3(100 \%)$ \\
\hline Retail Operations & - & - & 5 & $2(40 \%)$ \\
\hline Sport and Recreation & - & - & 2 & $2(100 \%)$ \\
\hline
\end{tabular}




\section{Notes:}

${ }^{1}$ One participant placed in an Optical Mechanical apprenticeship completed a Business Administration Traineeship

${ }^{2}$ One of the GTOs participating in the project went into administration and ceased operation partway through this project. Progress and some additional information among the apprentices and trainees placed by this GTO is missing as a result of this and the completion rates are based on the 118 individuals tracked.

${ }^{3}$ Percentage calculated based on 89 participants.

${ }^{4}$ Percentage calculated based on 29 participants.

${ }^{5}$ Percentage calculated based on 64 participants.

${ }^{6}$ Percentage calculated based on 10 participants.

${ }^{7}$ Percentage calculated based on 36 participants.

${ }^{8}$ Percentage calculated based on 6 participants.

${ }^{98}$ Percentage calculated based on 82 participants.

${ }^{10}$ Percentage calculated based on 18 participants. 


\section{References}

[1] Australian Bureau of Statistics, Disability, ageing and carers, Australia: summary of findings, 2003, ABS cat. no. 4430.0, Canberra: ABS, 2004.

[2] Australian Institute of Health and Welfare, Australia's welfare 2009, Canberra: AIHW, 2009.

[3] Australian National Training Authority, Bridging pathways: national strategy, from 2000 until 2005; the national strategy for increasing opportunities for people with a disability in vocational education and training, Brisbane: ANTA, 2000.

[4] Australian National Training Authority, Bridging pathways: revised blueprint, Brisbane: ANTA, 2004.

[5] Australian Qualifications Framework Advisory Board, Australian qualification framework: implementation handbook ( $4^{\text {th }}$ Edition), Carlton South: AQF Advisory Board, 2007.

[6] K. Ball, Outcomes for people with a disability in vocational education and training, Pathways 5 national conference: Reviewing the past - adapting to the future, Canberra 6-8 December 2000, http://www.adcet.edu.au/StoredFile.aspx?id=1331\&fn=Ball.pdf, retrieved November 18, 2009.

[7] K. Ball, Factors influencing completion of apprenticeships and traineeships, Australian Labour Market Research Workshop, Perth 6-7 December 2004, http://www.ncver.edu.au/pubs/confs/KBall_ALMRW2004.pdf, retrieved November 18, 2009.

[8] T. Bellamy, L. Rhodes, D. Mank and J. Albin, Supported employment: a community implementation guide, Baltimore: Paul H. Brookes, 1988. 
[9] J. Borthwick, D. John and M. Werner, Evidence of skill shortages in the automotive trades, Leabrook: NCVER, 2000.

[10] R. Cameto, C. Marder, M. Wagner and D. Cardoso, Data brief: youth employment: a report from the National Longitudinal Transition Study-2 (December 2003), http://www.ncset.org/publications/viewdesc.asp?id=1310, retrieved November 18, 2009.

[11] T. Cavallaro, P. Foley, J. Saunders and K. Bowman, People with a disability in vocational education and training: a statistical compendium, Adelaide: NCVER, 2005. [12] Clarius Group and KPMG Econtech, Clarius skills index: December quarter (January 2010), http://www.clarius.com.au/PDF/Clarius\%20Skills\%20Index_December\%202009\%20Q uarter.pdf, retrieved February 24, 2010.

[13] S. Earwaker and T. Gilbert, Services for people with a learning disability, in: Learning disabilities: practice issues in health settings, M. Todd and T. Gilbert, eds., London: Rutledge, 1995.

[14] M.W. Gold, The Austin project: final report, New York: Marc Gold and Associates, 1980.

[15] Group Training Australia Ltd., Policy statement - a better skilled workforce, http://www.grouptraining.com.au/policy/downloads/GTA\%20Policy\%20Statement\%20 REVISED\%20FINAL.pdf, retrieved March 18, 2010.

[16] B. Hernandez, M.J. Cometa, J. Velcoff, J. Rosen, D. Schober and R.D. Luna, Perspectives of people with disabilities on employment, vocational rehabilitation, and the Ticket to Work program, Journal of Vocational Rehabilitation, 27(2007), 191-201. 
[17] Human Rights and Equal Opportunity Commission, Issues Paper 1: Employment and disability - the statistics (2005),

http://www.hreoc.gov.au/disability_rights/employment_inquiry/docs/Issue1_statistics.p df, retrieved December 4, 2009.

[18] K. Jones, Improving participation in vocational education and training and employment for students with disabilities, Intellectual Disability Australasia 30 (2005), $12-14$.

[19] G. Lewis, New avenues to open employment, in: Project Employment Monographs, 1986-87, J.R. Cooper, ed., Perth: PE Publications, 1987.

[20] G. Lewis, Key success factors in placing and support apprentices with disabilities through group training: findings of a national study (2002), http://www.gtaltd.com.au/projects/downloads/GTA\%20Disabilit.pdf, retrieved December 4, 2009.

[21] G. Lewis, Key success factors in placing and supporting new apprentices with disabilities through group training: a best practice guide. Brisbane: Australian National Training Authority, 2002.

http://www.gtaltd.com.au/projects/downloads/best_practice_guide.pdf, retrieved December 4, 2009.

[22] G. Lewis, Supporting people with disability in apprenticeships and traineeships: the WA disability partnership project: final report, Subiaco: EDGE Employment Solutions, 2008.

[23] G. Lewis, P. Goff and M. Tarzia, Increasing the participation of people with disabilities in apprenticeships: final report (2002), 
http://www.edge.org.au/researchpdf.php?goto=Report_1.pdf, retrieved December 4, 2009.

[24] G. Lewis and J. Priday, National disability partnerships project: preliminary findings (2008), http://www.edge.org.au/researchpdf.php?goto=Report_5.pdf, retrieved December 4, 2009.

[25] G.M. Lewis and S.K. Robertson, Finding a job: keeping a job (6 $6^{\text {th }}$ Edition), Subiaco: PROEM Publications, 2008.

[26] E.P.Y. Li, Self-perceived equal opportunities for people with intellectual disability, International journal of Rehabilitation Research 27(2004), 241-245.

[27] R.G. Luecking, Emerging employment views of people with disabilities and the future of job development, Journal of Vocational Rehabilitation 29(2008), 3-13.

[28] R.L. Luftig and D. Muthert, Patterns of employment and independent living of adult graduates with learning disabilities and mental retardation of an inclusionary high school vocational program, Research in Developmental Disabilities 26(2005), 317-325. [29] C. Mcloughlin, B. Garner and M. Callahan, Getting employed, staying employed, Baltimore: Paul H. Brookes, 1987.

[30] M. Mooney and L. Scholl, Profiles of resilience: students with disabilities in Wisconsin's youth apprenticeship program, Annual meeting of the American Educational Research Association: 1-6 April, 2002. New Orleans, Louisiana: Education Resources Information Centre, http://www.eric.ed.gov/ERICWebPortal/custom/portlets/recordDetails/detailmini.jsp?_n fpb=true\&_\&ERICExtSearch_SearchValue_0=ED467716\&ERICExtSearch_SearchTyp e_0=no\&accno=ED467716, retrieved December 4, 2009. 
[31] R. Naidu, VET glossary (2008), Adelaide: NCVER, http://www.ncver.edu.au/res/glossary/Glossary.pdf, retrieved December 10, 2009. [32] National Association for Industry-Education Cooperation, Participation of the handicapped in apprenticeships: the state-of-the-art, Buffalo, New York: National Association for Industry-Cooperation, 1987.

[33] National Centre for Vocational Education Research, Australian vocational education and training statistics: apprentices and trainees, 2008-annual, Adelaide: NCEVER, 2009.

[34] National Centre for Vocational Education Research, Students with a disability (December 3, 2009), http://www.ncver.edu.au/statistic/publications/2157.html, retrieved December 10, 2009.

[35] L. Newman, M. Wagner, R. Cameto and A.-M. Knokey, The post-high school outcomes of youth with disabilities up to 4 years after high school: a report from the National Longitudinal Transition Study-2 (NLTS2) (April 2009), http://www.nlts2.org/reports/2009_04/index.html, retrieved December 10, 2009. [36] Organisation for Economic Co-operation and Development, Transforming disability into ability: policies to promote work and income security for disabled people, Paris: OECD Publications, 2003.

[37] Organisation for Economic Co-operation and Development, Sickness, disability and work: breaking the barriers: vol. 2: Australia, Luxembourg, Spain and the United Kingdom, Paris: OECD Publications, 2007.

[38] A. Smith, Evidence of skill shortages in the engineering trades, Leabrook: NCVER, 2002. 
[39] M. Wagner, The benefits of secondary vocational education for young people with disabilities (1991), http://www.eric.ed.gov/ERICDocs/data/ericdocs2sql/content_storage_01/0000019b/80/ 23/18/6d.pdf, retrieved December 10, 2009.

[40] M. Wagner, J. Blackorby, R. Cameto and L. Newman, What makes a difference? influences on postschool outcomes of youth with disabilities: the third comprehensive report from the National Longitudinal Transition Study of special education students: (1993), http://www.eric.ed.gov/ERICDocs/data/ericdocs2sql/content_storage_01/0000019b/80/ 15/21/eb.pdf, retrieved December 10, 2009.

[41] P. Waterhouse, H. Kimberley, P. Jonas and J. Glover, What would it take? employer perspectives on employing people with a disability, Adelaide: NCVER, 2010. [42] P. Wehman and S. Moon, Vocational rehabilitation and supported employment, Baltimore: Paul H. Brookes, 1988. 